\title{
A ESPERANÇA COMO AJUSTAMENTO CRIATIVO: REFLEXÕES DOS PROCESSOS DE SAÚDE, DOENÇA E MORTE EM GESTALT TERAPIA
}

\author{
Hope as creative adjustment: reflections of health, disease and death processes in Gestalt \\ Therapy
}

La esperanza como ajuste creativo: reflexiones de los procesos de salud, enfermedad y muerte en Gestalt Terapia

\begin{abstract}
Resumo: A esperança pode ser definida como uma expectativa voltada ao momento futuro que pode servir de fator protetivo às adversidades. Este trabalho buscou investigar a esperança no contexto dos processos de saúde, doença e morte a partir do conceito de ajustamento criativo que origina-se de uma perspectiva de base fenomenológica desenvolvida por Fritz Perls (1977). Por meio de uma revisão narrativa de caráter qualitativo, buscou-se definir o que está sendo veiculado sobre esperança somado à psicologia hospitalar nas bases de dados Scielo, PsycINFO e Google Acadêmico. Utilizaram-se os artigos publicados do período de 2001 a 2018. Os materiais encontrados foram descritos e discutidos através dos preceitos da Gestalt Terapia. A partir das reflexões teóricas realizadas entende-se que a esperança pode servir como uma forma de ajustar-se criativamente a um período crítico de doenças graves ou terminalidade posto que se faz de suporte para o enfrentamento da realidade. Espera-se que este trabalho possibilite que o profissional de saúde realize reflexões, redirecionando o olhar para os funcionamentos saudáveis nos processos de saúde e doença de modo que vise fortalecer as potencialidades e a retomada de respostas espontâneas e criativas de seus pacientes.
\end{abstract}

Palavras-chave: Esperança; Ajustamento Criativo; Gestalt Terapia; Psicologia Hospitalar; Morte.

\begin{abstract}
Hope can be defined as a forward-looking expectation that can serve as a protective factor to adversity. This work sought to investigate hope in the context of health, disease and death processes from the concept of creative adjustment that originates from a phenomenological perspective developed by Fritz Perls. Through a qualitative narrative review, we sought to define what is being published about hope in addition to hospital psychology in the databases Scielo, PsycINFO and Google Scholar. Materials published from the period 2001 to 2018 were used. The materials found were described and discussed through the precepts of Gestalt Therapy. From the theoretical reflections carried out it can be understood that hope can serve as a way of creatively adjusting to a critical period of serious illnesses or terminality, since it becomes a support for facing reality. It is hoped that this work will enable the health professional to make reflections, redirecting the look to healthy workings in health and illness processes in order to strengthen the potentialities and the recovery of spontaneous and creative responses of their patients.
\end{abstract}

Keywords: Hope; Creative Adjustment; Gestalt Therapy; Hospital Psychology; Death.

Resumen: La esperanza puede ser definida como una expectativa volcada al momento futuro que puede servir de factor protector a las adversidades. Este trabajo buscó investigar la esperanza en el contexto de los procesos de salud, enfermedad y muerte a partir del concepto de ajuste creativo que se origina desde una perspectiva de base fenomenológica desarrollada por Fritz Perls (1977). Por medio de una revisión narrativa de carácter cualitativo, se buscó definir lo que está siendo vehiculado sobre esperanza sumado a la psicología hospitalaria en las bases de datos Scielo, PsycINFO y Google Académico. Se utilizaron los artículos publicados del período de 2001 a 2018. Los materiales encontrados fueron descritos y discutidos a través de los preceptos de la Gestalt Terapia. A partir de las reflexiones teóricas realizadas se entiende que la esperanza puede servir como una forma de ajustarse creativamente a un período crítico de enfermedades graves o terminalidad puesto que se hace de soporte para el enfrentamiento de la realidad. Se espera que este trabajo posibilite que el profesional de salud realice reflexiones, redireccionando la mirada hacia los funcionamientos saludables en los procesos de salud y enfermedad de modo que viste fortalecer las potencialidades y la reanudación de respuestas espontáneas y creativas de sus pacientes.

Palabras-clave: Esperanza; Ajuste Creativo; Gestalt Terapia; Psicología Hospitalaria; Muerte. 
Pandora, a primeira mulher criada no mundo, recebeu de Zeus uma caixa que lhe era proibido abrir. E roída pela curiosidade, a tentação foi maior do que o autocontrole. Pandora abriu a caixa. A qual continha todas as graças e desgraças humanas. Num instante, todos os males se espalharam pelo mundo, e as graças escaparam e se perderam, menos uma: a esperança. Sem esperança, os mortais não conseguiriam resistir. (Brandão, 1992)

O presente artigo tem por objetivo integrar o conceito da esperança com o de ajustamento criativo por meio de uma revisão narrativa de literatura e reflexão teórica com base na Gestalt Terapia. Dar-se-á enfoque ao conceito de esperança referente aos processos de saúde, doença e morte que podem ser vislumbrados no contexto hospitalar dentre os pacientes internados, seus familiares e profissionais da instituição. Segundo o dicionário da língua portuguesa a esperança conceitua-se como a crença de que um desejo se torne realidade, vincula-se ao sentimento de quem vê como possibilidade a realização de algo que ainda não aconteceu; uma expectativa voltada ao momento futuro. Vista como um fenômeno dinâmico e multidimensional para a Psicologia, a esperança pode ser definida como a perspectiva para a realização de objetivos reais, originando a energia necessária para o movimento de uma ação (Snyder \& Lopez, 2009) bem como pode funcionar como um fator protetivo às adversidades (Mednick, Cogen, Henderson, Rohrbec, Kitessa, \& Streisand, 2007). Em última análise, segundo o filósofo Ernst Bloch (2005) a esperança é um afeto prático, militante. De toda forma, a esperança implica em esperar. O ser humano está sempre à espera de algo, seja a espera de uma boa notícia, das férias do trabalho, do nascimento de um filho, da mudança política de um país, por condições melhores de saúde. Até mesmo em situações de revolução e transformações pessoais ou sociais a esperança está implícita (Menezes, 2013).

Nos processos de morte e morrer Kubler-Ross (2005) refere cinco estágios de elaboração do luto, são esses: 1) negação, que refere-se à uma defesa psíquica no sentido de não entrar em contato com a situação; 2) raiva, que diz respeito às sensações de injustiça, inconformidade com a situação; 3) barganha, o qual refere-se ao período de negociação para fins de permutar sua situação por outra mais acessível; 4) depressão, fase de isolamento social e reflexão sobre a situação; e, 5) aceitação, quando o indivíduo entra em contato com a realidade de forma mais fluida e consegue enxergá-la de modo mais natural. Tais fases ou estágios possuem duração variável, podendo substituir um ao outro ou se encontrarem em algum momento, contudo, segundo a autora, o único aspecto que persiste em todos os estágios é o fio da esperança (Kubler-Ross, 2005), pois mesmo seus pacientes mais conformados ou realistas deixaram-se abertos para uma possibilidade de cura.
Ainda, o processo de luto pode ser influenciado pela relação com a pessoa perdida e a natureza dessa relação, se a morte ocorreu de forma abrupta ou expectável, as variáveis da personalidade bem como os antecedentes históricos da pessoa enlutada (Kovács, 2007). As mudanças sociais que estamos vivenciando podem dificultar a elaboração da morte, posto que a urbanização, a velocidade imposta pela produtividade e os avanços médicos levaram à desvalorização dos rituais de despedida; dessa forma, muitas pessoas sentem-se solitárias ao vivenciar o sofrimento ocasionado pela perda (Kovács, 2003).

Segundo a autora, não refletir sobre a nossa terminalidade dificulta o processo de enfrentamento dessa e até mesmo influi na forma como nos comportamos ao longo da vida, sendo assim, propõe em seus estudos a educação para a morte. A educação para a morte visa em abrir espaços de comunicação cotidiana sobre a terminalidade da vida e também trazer reflexões que surjam das próprias experiências vivenciadas (Kovács, 2003); baseia-se no autoconhecimento, nos questionamentos e, sobretudo, na busca de um sentido para a vida. Faz-se possível pensar que o modo com que o indivíduo encara o sentido da sua vida influi substancialmente no modo com que ele espera a sua morte.

Snyder, Cheavens, e Sympson (1997) consideram a esperança uma variável cognitivo-motivacional essencial à teoria da motivação, posto que ela reflete as avaliações subjetivas acerca da capacidade diante de um objetivo. Para Snyder (2000), os componentes principais da esperança dizem respeito às metas de curto ou longo prazo e sua probabilidade de serem alcançadas, ao encontro de caminhos possíveis para alcançar essas metas, e sobretudo relacionado à visualização de caminhos alternativos quando se encontra impedimentos nos primeiros, e a crença de que o indivíduo conseguirá sustentar o esforço necessário para percorrer essa trajetória.

Segundo Kubler-Ross (2005) a esperança foi, para alguns de seus pacientes, um processo de racionalização do sofrimento, mas para outros continuou sendo uma forma de negação temporária, porém necessária, deste, uma vez que o que sustenta esse tipo de sofrimento é a esperança de que se aguentarem mais um tempo o esforço será compensado. Os conflitos que se originam do sentimento de esperança se distribuem de duas maneiras: quando a família ou a equipe hospitalar substituem a esperança pela desesperança para o paciente, quando essa ainda lhe era fundamental; ou, quando a família apega-se disfuncionalmente à esperança por não conseguir lidar com a realidade, sendo que o próprio paciente já se apresentava em contato com a sua terminalidade.

Ainda, há casos em que os pacientes agarram-se à esperança de cura e lutam por essa até o fim, dificultando a aproximação ao estágio de aceitação; a família, bem como a equipe de saúde, por terem suas próprias introjeções sobre os processos de morte, va- 
lidam esse comportamento e atribuem significados de força e resistência a esses pacientes, encorajando-os pela luta interminável, transmitindo a ideia que a aceitação da morte seria uma decepção para ou rejeição à família (Kubler-Ross, 2005).

Por outro lado, segundo a autora, mesmo os pacientes que não possuem terapêutica curativa, os que estão em cuidados paliativos, precisam constatar na equipe de saúde a certeza de que estão recebendo o melhor tratamento para que mantenham suas projeções ao futuro e não se sintam desprezados ou abandonados (Kubler-Ross, 2005). A parada de investimento técnico e emocional em um paciente, dependendo de seu histórico de vida, pode fazer com que esse se entregue e encontre mais brevemente a morte, pois não terá o fio de esperança que lhe dá o suporte necessário para continuar (Mendes, Lustosa, \& Andrade, 2009).

O fenômeno da esperança, sobretudo nos processos de morte e morrer, pode ser explorado por meio de perspectivas diversas; neste estudo buscou-se enxergá-lo através de uma teoria que tem como sustentação a busca pelo o que há de saudável e funcional no ser humano em seus modos de viver e até mesmo em seu sofrimento. Baseada em vários princípios, sendo dois deles a Teoria Organísmica e a Fenomenologia, a Gestalt Terapia entende que nenhum organismo é autossuficiente ou capaz de funcionar isoladamente, pois busca satisfazer as suas necessidades no meio, dessa forma, vê-se uma relação dialética e interdependente entre organismo e meio formando o que é chamado de campo. Esse campo só pode ser experienciado através de um processo denominado contato; quando emerge do campo algo novo que é assimilado de forma ativa, o contato acontece (Perls, Hefferline, \& Goodman, 1997).

Visto que a experiência humana se dá na fronteira de contato, visualizar-se nessa fronteira de contato em ação dá origem ao que chamamos em Gestalt Terapia de self (Perls, Hefferline, \& Goodman, 1997). A "qualidade" desse contato, ou seja, a forma como esse contato acontece é o que podemos chamar de ajustamento criativo. De acordo com Cardella (2014, p. 114), "ajustar-se criativamente é "a capacidade de pessoalizar, subjetivar e se apropriar das experiências que acontecem no encontro com a alteridade, processo contínuo no campo organismo/meio". Ajustamento, pois diz respeito a uma ação que dá forma conforme a experiência vivida; e, criativo, pois trata-se de uma resposta nova feita da melhor maneira possível para aquele momento. Enquanto o ajustamento garante a dimensão da realidade, a criação vai ao encontro da dimensão da fantasia e amplia as possibilidades (Robine, 2006). O ajustamento sem criatividade é uma adaptação excessiva, uma cristalização, já a criatividade sem o ajustamento se revela sem funcionalidade e estéril (Cardella, 2014).

As formas de contato, segundo Perls, Hefferline e Goodman (1997), se qualificam de cinco for- mas: confluência, introjeção, projeção, retroflexão e egotismo; podendo essas serem ajustadas de modo criativo ou serem disfuncionais. Saudável e criativo entendemos como uma integração no campo que permite a fluidez no fluxo figura e fundo, dessa forma, sintonizados com as nossas capacidades fazemos escolhas a partir das possibilidades que se apresentam e melhor respondam a nossa necessidade (Schillings, 2014). O contato disfuncional se apresenta quando há uma inibição do excitamento frente a uma nova figura, interrompendo o fluxo entre figura e fundo, o que não desenvolve o ímpeto necessário para a ação levando à repetição de comportamentos que, por sua vez, não são adequados à nova situação. Essas formas de interrupção do contato também podem ser entendidas como mecanismos neuróticos (Perls, 1981).

O conceito de saúde, para a Gestalt Terapia, não se encontra na "normalidade" imposta pela vida cotidiana uma vez que essa mais se enquadra em um estado crônico de desequilíbrio no qual a satisfação nunca é alcançada (Latner, 1994), a normalidade de nossa atual situação é epidêmica. A saúde, nesse sentido, aparece como aquilo de melhor que podemos fazer diante dessa realidade, às vezes doentia, que se impõe. Saúde é uma vivência integral, a identificação com nossas funções vitais e nossa capacidade, é perder a razão e recuperar os sentidos (Perls, 1977). Na abordagem gestáltica, a formação e destruição satisfatórias de gestalten é uma definição funcional de saúde (Latner, 1994), posto que significa que, a partir disso, há uma tendência de que a experiência tenha por si uma profundidade e que leve à satisfação.

Fomentar a reflexão de como a esperança pode apresentar-se enquanto forma de contato criativo ou disfuncional nos processos de saúde, doença e terminalidade torna-se fundamental uma vez que os profissionais de saúde podem vislumbrar suas intervenções de acordo com a necessidade real de seus pacientes, direcionando o olhar para aquilo que há de saudável e funcional nos seus modos de ver e viver a vida.

\section{Método}

Optou-se em realizar uma Revisão Narrativa de Literatura uma vez que objetivo foi de compreender o que a produção científica revela a respeito da esperança relacionada ao contexto de saúde e doença sem a aplicação de buscas sofisticadas e exaustivas. Acredita-se que esse tipo de revisão atende a necessidade de conhecer os diferentes estudos que apresentam o fenômeno da esperança e também atende de forma mais eficaz estudos relacionados às áreas de ciências humanas e sociais. Além disso, não houve necessidade de elencar critérios sistemáticos para minimizar possíveis tendenciosidades nem de solicitar a avaliação de juízes para o acompanhamento da revisão. 
Uma vez que não se encontraram registros na literatura que articulem o conceito de esperança com os fundamentos da Gestalt Terapia, realizar uma Revisão Narrativa torna-se relevante por oferecer subsídios para reflexões teóricas que retornem o olhar para os funcionamentos saudáveis dentro dos processos de saúde-doença. Além disso, seus resultados podem evidenciar lacunas existentes na literatura nacional, contribuindo para a formulação de novos estudos relacionados à temática que visem aprofundar especificidades do assunto (Galvão, Sawada, \& Trevizan, 2004).

\section{Descritores:}

Como palavras-chave utilizaram-se descritores em português validados na plataforma DeCS (Descritores em Ciências da Saúde): esperança, morte, doença e 'psicologia hospitalar'. Os descritores foram colocados em duplas, entre os termos utilizou-se o operador AND a fim de encontrar pesquisas que relacionem os descritores selecionados.

\section{Bases de dados e/ ou revistas:}

Foram selecionadas as bases de dados que continham maior abrangência de publicações nas áreas de Psicologia e Saúde, por serem principais áreas de produção científica referentes ao tema da pesquisa: 1) IndexPsi, por ser uma base de dados que reúne, organiza e divulga a literatura técnico-científica nacional de periódicos publicada na área da Psicologia; 2) Scielo, por ser uma biblioteca eletrônica que permitirá a exploração da produção científica nacional em diversas áreas; 3) Google Acadêmico por possuir um número significativo de citações conferindo assim uma relevância maior na pesquisa.

\section{Estratégias de busca:}

1. Campos de busca: Em todas as bases de dados realizaram-se as buscas a partir dos campos título, resumo e palavras-chave em vista da escassez de estudos sobre os fenômenos, para obter um resultado amplificado que permitisse encontrar estudos relevantes mesmo que menos específicos.

2. Procedimentos de busca: Para todas as bases utilizou-se o cruzamento das palavras-chave esperança, morte, saúde e 'psicologia hospitalar', combinada a palavra esperança em par com morte, saúde ou 'psicologia hospitalar'. Como operador boleano optou-se pelo AND a fim de encontrar pesquisas que interseccionem os fenômenos abordados.

3. Período da busca: Tendo em vista a escassez de estudos acerca da esperança, sobretudo no âmbito da Psicologia, optou-se por buscar todos os trabalhos publicados no século XXI, demarcando o período de busca inicial nos anos 2011 abrangendo todas as publicações até 30 de setembro de 2018.

4. Áreas das bases: A fim de filtrar os resultados gerados pelas bases de dados abordaram-se os estudos das áreas de Psicologia e Saúde uma vez que essas são as principais áreas a relacionarem o conceito de esperança como fenômeno inerente ao processo saúde-doença, o que corresponde ao objetivo da revisão.

5. Tipos de publicações: Foram selecionados artigos empíricos, pois oferecem uma articulação teórica com o fenômeno, e, ainda, porque são avaliados por pares e apresentam alto grau de confiabilidade.-

6. Idioma(s): Selecionaram-se estudos apenas no idioma português tendo em vista que o interesse da pesquisa é abordar os estudos relevantes acerca da esperança que estejam disponíveis nas bases nacionais e que representam a cultura brasileira nas formas de vivenciar os processos de saúde e doença.

Critério de inclusão: 1) artigos empíricos; 2) publicações que estejam relacionadas ao objetivo da pesquisa; 3) acesso aos resumos completos em português; 4) estudos das áreas de Psicologia, Sociologia ou Saúde.

Critérios de exclusão: 1) Estudos com temáticas que não correspondem à pergunta de pesquisa; 2) Estudos com descritores que apresentem outros significados que não àqueles do objetivo da pesquisa; 3) Outros tipos de publicações (livros, capítulos de livros, resumos de anais, teses, dissertações, entre outros); 4) Artigos duplicados.

\section{Procedimentos de análise:}

Como início do procedimento de análise realizou-se uma leitura seletiva dos títulos e resumos dos estudos encontrados de acordo com os objetivos da pesquisa. Em seguida, recuperaram-se os artigos selecionados na íntegra a fim de aplicar os critérios de inclusão e exclusão, para assim constituir o corpus que será utilizado como material de análise. Com os estudos recuperados, realizou-se uma leitura mais íntegra e detalhada a fim de identificar palavras-chaves, objetivos, procedimentos metodológicos e principais resultados. A partir da organização desses dados fez-se possível descrever os achados de produção científica nacional acerca da esperança a âmbito dos processos de saúde, doença e terminalidade no contexto hospitalar.

\section{Resultados e Discussão}

Ao todo foram encontrados 110 artigos no Scielo e 20 artigos na base IndexPsi que continham os descritores em seu título e/ou resumo. O Google Acadêmico possui uma busca mais extensiva e não permite a utilização de filtros, por isso encontraram-se 108.790 estudos através dos buscadores, mas pela inviável análise de todos os estudos optou-se por explorar apenas os 30 estudos mais relevantes de cada combinação de descritores. Destaca-se que esse número corresponde à soma das quantidades encontradas por cada descritor utilizado, ocorrendo repetições caso um mesmo trabalho aparecesse como resultado de dois ou mais descritores. 
Todos os estudos elencados passaram por uma leitura seletiva dos títulos e conteúdos gerais a fim de verificar se cabiam aos critérios de inclusão. Após essa leitura, apenas algumas pesquisas foram consi- deradas potencialmente relevantes. A Tabela 1 mostra o número total de pesquisas encontradas nas bases de dados e a quantidade considerada potencialmente relevante utilizando os termos indutores combinados.

\begin{tabular}{|c|c|c|c|c|}
\hline & & Busca total & & Potencialmente relevantes \\
\hline \multirow{3}{*}{ SciELO } & esperança + morte & 66 & & 6 \\
\hline & esperança + saúde & 144 & & 15 \\
\hline & $\begin{array}{c}\text { esperança + 'psicologia } \\
\text { hospitalar' }\end{array}$ & 2 & & 0 \\
\hline \multirow{3}{*}{ IndexPsi } & esperança + morte & 5 & & 0 \\
\hline & esperança + saúde & 15 & & 0 \\
\hline & $\begin{array}{c}\text { esperança + 'psicologia } \\
\text { hospitalar' }\end{array}$ & 0 & & 0 \\
\hline \multirow{3}{*}{ Google Acadêmico } & esperança + morte & 47.100 & 30 & 6 \\
\hline & esperança + saúde & 60.200 & 30 & 5 \\
\hline & $\begin{array}{c}\text { esperança + 'psicologia } \\
\text { hospitalar' }\end{array}$ & 1.490 & 30 & 7 \\
\hline
\end{tabular}

Tabela 1.

Número de referências encontradas e selecionadas na utilização dos indutores.

Realizada uma leitura integral dos 39 artigos considerados potencialmente relevantes encontrados nas 3 bases de dados, verificou-se que 4 não correspondiam aos critérios de inclusão, pois embora citassem em seu texto o construto esperança, o enfoque do conteúdo era em outros assuntos (cuidados paliativos, representações de morte, entre outros). Ainda, encontraram-se 5 estudos repetidos entre as bases de dados. Após a aplicação dos critérios de exclusão, a seleção finalizou em um total de trinta estudos.

Da leitura integral dos trinta artigos que abordavam o conceito de esperança verificou-se que a maior parte analisava a esperança relacionada aos pacientes; sejam esses nos mais diversos contextos: terminais, oncológicos, doenças crônicas, e também em suas diversas fases do ciclo de vida. Também se encontraram artigos que analisavam a esperança nos familiares e cuidadores de pessoas no processo de saúde-doença ou de profissionais de saúde que lidam diariamente com pessoas em período de terminalidade da vida. Ainda, encontrou-se uma reflexão teórica sobre historicidade e esperança.

Nos estudos que avaliam a esperança em pessoas em processo de doença nota-se, quase como um consenso, que essa atinge o binômio saúde doença de uma maneira positiva, auxiliando a pessoa a li- dar de uma forma mais saudável com seu futuro. Até mesmo, a esperança tem demonstrado o seu efeito terapêutico e aparece como uma forte estratégia de enfrentamento em diversas conjunturas, inclusive no momento de fim de vida (Pinto, Caldeira, \& Martins, 2012). Às vezes pode parecer um contrassenso ou inconveniência falar sobre esperança para pessoas cujo futuro pode ser encurtado em meses, semanas ou horas; entretanto, os estudos indicam que nos contextos de doenças graves, a esperança contribui significativamente para a adaptação à doença e ao tratamento e na melhora da qualidade de vida.

Cavaco, Guerreiro, Reis, Alves, Martins, e Santos (2010) indicaram que há aspectos como a espiritualidade, suporte social, características pessoais, planejamento com objetivos concretizáveis, novos significados de vida com o advento da doença, sentir-se escutado, qualidade de vida, entre outros, que se apresentam como promotores do sentimento de esperança. Já os sentimentos de abandono, isolamento, despersonalização dos cuidados, ostracismo pela família, falta de informações realistas e o medo, demonstram-se como aspectos que diminuem a projeção do sujeito quanto a seu futuro.

Em um estudo sobre a atitude atribuídas às mulheres com câncer de mama avançado, verificou-se que as participantes consideram que a informação 
adequada sobre as condições clínicas e possibilidades de sobrevivência dada pelos oncologistas é fundamental para a transmissão de esperança e o estabelecimento de planos adequados ao futuro real (Kiely et al., 2013). O profissional de saúde, por estar muito próximo ao cotidiano do paciente, pode servir como agente impulsionador do bem-estar e da esperança (Cavaco et al., 2010). O psicólogo, em especial, pode encontrar junto ao paciente, novas formas de significar a situação que este está vivenciando para que se faça possível o estabelecimento de ações voltadas ao futuro, mas, sobretudo, direcionadas a sua realidade no aqui e agora. Menezes (2013) entende que a esperança é uma categoria relacionada intimamente com a temporalidade uma vez que pressupõe a ideia de futuro; há em seu cerne a expectativa da realização de um desejo atual, mas em outro momento.

Quanto ao ciclo de vida, em um estudo realizado com crianças e adolescentes em recidiva oncológica, verificou que a maior dificuldade enfrentada recaiu diante da dimensão emocional, sobretudo relacionada à inconformidade de ter que passar novamente pelos desafios já enfrentados (Caires, Machado, Antunes, \& Melo, 2018). Dessa forma, notou-se uma maior dificuldade relacionada à manutenção da esperança conduzindo a menores perspectivas futuras e menos otimismo quanto à possibilidade de sucesso, especialmente nos pacientes adolescentes. Verifica-se que a continuidade da frequência escolar, sempre que possível, aparece como um fator importante nessa faixa etária uma vez que permite que a criança e o adolescente foquem na dimensão saudável de suas vidas, abrindo espaço para planejamentos futuros e promoção de esperança (Ciporah, Tadmor, \& Weyl Ben-Arush, 2012).

$\mathrm{O}$ apoio emocional à criança pode ser transmitido através de recursos lúdicos e de mensagens que retratem mais claramente a situação vivenciada, a esperança de um resultado satisfatório frente ao tratamento demonstra ser uma arma importante para o enfrentamento deste. Devido ao presente difícil, a esperança de um futuro é almejada pela criança sendo essencial para a superação do estresse físico e emocional vivenciado (Benedetti, Garanhani, \& Sales, 2014). A relação e a comunicação entre criança, seus cuidadores e equipe de saúde devem ser valorizadas e mantidas; Borges, Lima, e Dupas (2016) evidenciam que o próprio núcleo familiar entende que tanto os profissionais quanto a criança transmitem apoio e esperança para que a família encontre forças para continuar a caminhada.

Quanto à ação da esperança com os familiares ou cuidados de pessoas com doenças graves, o estudo de Espíndula e Valle (2002) demonstrou que mães de crianças com recidivas oncológicas, ao sentirem-se angustiadas pela incapacidade de compreenderem os pensamentos e sentimentos dos filhos, utilizavam a esperança como uma estratégia de enfrentamento, uma vez que precisavam de um alicer- ce que a fortalecessem para permanecerem firmes nos cuidados com os filhos.

Segundo Moreno, Jorge, e Moreira (2003) ver um filho entre a vida e a morte representa, na maioria das vezes, uma situação desesperadora; para minimizar o sofrimento e até mesmo a dor física e emocional, os pais apontam a esperança como caminho de um mundo compartilhado, de ser-com-outro. São os sentimentos de presença e segurança que sustentam o caminho de esperança que, por sua vez, sustenta o processo de cuidar (Moreno, Jorge, \& Moreira, 2003).

Entende-se que mesmo no processo de terminalidade e reconhecimento da família dos benefícios de um cuidado frente à morte, a morte é uma realidade que nunca será aceita uma vez que a maneira encontrada de perseverar é a manutenção da esperança ao longo do caminho. A família vai vivenciando os sentimentos de perda ao longo do processo da doença, e não somente após a morte do ente querido; fato que precisa ser reconhecido pelos profissionais que estarão prestando assistência à pessoa em situação de terminalidade, e, consequentemente, a sua família (Misko, Santos, Ichikawa, Lima, \& Bousso, 2015).

Segundo Borges, Alvis, e Dulci (2014) a morte em si muitas vezes não é o problema central para o paciente ou sua família, mas sim o medo de morrer acompanhado com os sentimentos de desesperança, desamparo, solidão. São os aspectos desagradáveis que acompanham o processo de morte e morrer que devem ser identificados pela equipe que os acompanha. O amparo e o cuidado não farão desaparecer a iminência da morte, mas iluminarão o restante de vida (Borges Alvis \& Dulci, 2014).

A intervenção com a família deve concentrar-se em seus pontos fortes, habilidades, ajustamentos saudáveis, ou seja, aquilo que os mantém vivendo, verificando se os recursos utilizados para o enfrentamento do processo de doença e de saúde são funcionais e ajustados à necessidade daquela família. Podem-se criar espaços de discussões entre família e equipe de saúde, permitindo a incorporação de seus modos de ver e viver a vida, reconhecendo suas competências e capacidades de autorregular-se frente às adversidades (Borges \& Silva, 2010).

No contexto das doenças crônicas há momentos em que o paciente e seus familiares, ou até mesmo os profissionais de saúde, perdem a esperança; sobretudo sob a iminência da terminalidade. Entretanto, a esperança pode transcender o desejo de cura e encaminhar-se para desejos mais concretos e de curto prazo como a ligação de alguém que se ama, ver o sol novamente, a diminuição de dor ou a espera de uma morte digna envolta das pessoas que se ama (Balsanelli, Grossi, \& Herth, 2011).

Dessa forma, o paciente e a família ajustam seus olhares para as pequenas conquistas adequadas às possibilidades reais da pessoa. Para familiares e entes queridos, o sentimento de esperança pode per- 
mitir que sua presença se faça presente sem que o sofrimento da possibilidade de perda se torne insuportável (Ferreira \& Mendes, 2013); apresentando-se como o suporte necessário para que no momento final ainda haja condições de acompanhar a terminalidade de seu ser querido e possibilitando, às vezes, a entrega para a expressão de sentimentos no momento da despedida.

Também, a promoção de esperança aparece como uma importante variável no autocuidado dos cuidadores uma vez que motiva o cuidador a realizar atividades de autocuidado para poderem cuidar, bem como instiga a mudança de agir perante a nova realidade e permite a aceitação e enfrentamento das dificuldades (Souza, Oliveira, Luchesi, Gratão, Orlandi, \& Pavarini, 2017). Segundo os autores, a dimensão espiritual demonstrou ser um recurso de esperança e essencial na atribuição de significados às vivências enfrentadas; nos momentos de dificuldade, os cuidadores encontraram na fé uma maneira de cuidarem de si mesmos.

Para os profissionais, o despreparo para lidar com situações de doenças graves ou terminalidade pode ter duas consequências, de acordo com Quintana, Kegler, Santos, e Lima (2006), a primeira refere-se à sensação de fracasso frente a missão de curar o doente podendo resultar em abandono do paciente; e a segunda, refere-se ao afastamento desse profissional da condição de humano que o paciente apresenta, impedindo-o de conhecer a história desse paciente, suas queixa e esperanças, conhecimento esse que poderia auxiliar o paciente a aproximar-se de sua terminalidade de forma digna. Como já mencionado, as pessoas em condição de adoecimento grave precisam constatar na equipe de saúde o investimento técnico e emocional necessário para que não se sintam desprezadas ou abandonadas e continuem a investir em sua vida, por mais breve que esta seja (Kubler-Ross, 2005).

Segundo Latner (1994), a saúde diz sobre a capacidade de sair inteiro apesar das tropeçadas, ou seja, não significa ignorar os obstáculos ou que eles simplesmente irão desaparecer, mas sim encará-los com todos os nossos recursos. É preciso manter contato com aquilo que é importante para si e assim termos maior clareza das nossas necessidades aceitando aquilo que somos no momento presente posto que nossas necessidades estão ancoradas nas vivências do aqui e agora.

Diante desses apontamentos, como não enxergar a esperança como um ajustamento criativo no processo de saúde, doença e terminalidade? São os ajustamentos criativos que atuam no processo de autorregulação do organismo na medida em que é através do potencial criativo de inventar novos modos de interação com o meio que se estabelece o equilíbrio entre aquilo que se necessita com aquilo que o meio dá como possibilidade (Lima, 2014).

Para a Gestalt Terapia os conceitos de saúde e doença não são estáticos e dizem respeito às formas por meio das quais o organismo tenta encontrar um sentido único para a sua existência na medida em que busca constantes trocas com o seu contexto (Fukumitsu, 2009). Quando a pessoa se relaciona com e no ambiente pode cristalizar seus modos de interação, ou flexibilizar o contato de forma criativa (Perls, 1988); dessa forma, os processos de saúde e doença são visualizados de uma perspectiva dinâmica, sendo possíveis e caracterizados por meio da interação.

Estes processos envolvem uma complexidade de sentimentos, em alguns momentos predominarão sentimentos de esperança relacionados à cura mesmo em situações de prognósticos desfavoráveis; em outros, a sensação de angústia diante da impotência em relação à deterioração física assumirá o controle e dará lugar a sentimentos destrutivos que levarão à aniquilação (Ferreira \& Mendes, 2013). Ainda, sentimentos de gratidão, conforto e amor podem surgir frente ao reconhecimento dos cuidados que lhe estão sendo dirigidos por parte de familiares, seres queridos e equipe de saúde.

É entre a negação da terminalidade ou das perdas e o prenúncio de luto que se encontra a esperança saudável. Naturalmente, é comum que se pendule pelos dois polos, contudo, quando se estabelece um fluxo equilibrado entre a polarização é possível instaurar a habilidade criativa e a percepção aprofundada da relação entre organismo e meio. Na fixação da negação ou no prenúncio de luto cria-se um vazio estéril que aprisiona e impede a visualização de novas formas de ser. A medida em que se faz possível a fluidez entre norte e sul, traz-se à tona o que é chamado em Gestalt Terapia de vazio fértil, no qual há o estabelecimento da espontaneidade e despertar dos sentidos frente aos novos acontecimentos de se impõe (Perls, 1977).

Até mesmo a negação ante o adoecimento ou o prenúncio de luto, se temporários, podem ser visualizados como ajustamentos criativos já que podem ser compreendidos como a melhor forma possível que a pessoa encontrou de dar conta de uma determinada situação, e talvez seja por esse caminho que o gestalt terapeuta encontre o fio que chegará à gestalt em aberto. Cada ser no mundo é único e possui sua própria, e melhor, forma de estabelecer contato com o mundo. $\mathrm{E}$, mesmo que seu ajustamento seja disfuncional em alguns momentos, entende-se que este utilizou os recursos que possuía para fazer o melhor que podia no aqui-agora (Silva \& Alencar, 2011).

Muitas vezes profissionais de saúde enxergam a espera por um milagre, por parte de seu paciente ou familiares desse, como uma forma de negação da realidade imposta pela doença. Contudo, percebe-se que é justamente nesses casos que a realidade se faz mais imposta, uma vez que é através do entendimento de que a cura não está ao alcance da ciência que se entrega a espera nas mãos da espiritualidade como 
último recurso viável. Pendulamos entre o milagre e o entendimento da doença especialmente por causa da esperança; se conseguirmos acompanhar nossos pacientes nesse ir e vir, estamos lhe presenteando com o que de melhor temos a oferecer: o caminhar em conjunto com suas reais e atuais necessidades.

Às vezes é necessário tempo para que se encontrem recursos para o enfrentamento de situações difíceis; cabe aqui ressaltar que esse tempo não deve ser estimado pelo profissional de saúde, pois é o paciente ou o familiar que indicará o tempo que necessita para ajustar-se à nova realidade que se depara. O desrespeito ao tempo necessário para a autorregulação estará na contramão do apoio e do cuidado, e pode interromper o sistema self no fechamento de uma figura, violentando o respeito de ser o que se é, retirando do indivíduo a sua identificação com aquilo que é seu, seus desejos, seus significados, suas necessidades, fragilizando o indivíduo e lhe roubando a autonomia (Schillings, 2010).

Segundo Benzein, Norberg e Saveman (2001), a dualidade entre o desejo de cura e o querer preparar-se para a morte faz parte da ontologia que acompanha o ser humano em seu ciclo de vida. Dessa forma, enfoca-se a necessidade de vislumbrar com os pacientes as esperanças que possam ser traduzidas em planejamentos de curto prazo redefinidos diariamente a fim de obter a melhor qualidade de vida possível no processo de terminalidade. Ressalta-se aqui que viver com esperança difere de viver com ilusão; faz-se possível encarar a finitude e ter a esperança de viver o tempo que lhe resta da melhor forma possível; ajustando-se criativamente a cada instante que se apresenta, capturando para si um novo significado de viver o tempo e de sentido da vida.

$\mathrm{Na}$ atuação profissional, mostra-se relevante propiciar experiências que venham potencializar o paciente no sentido de experimentar novas formas de solucionar um acontecimento (Lima, 2014). O ajustamento criativo, funcional e saudável bem como a autorregulação adequada se dão em um fluxo permanente de transformações em busca do novo, despadronizando a cristalização de ações antigas para acontecimentos novos, permitindo que a expressão criativa seja capturada no encontro com o meio, que é sempre em alguma medida novo, de maneira harmônica.

Cabe também ressaltar que o profissional que lidará com pessoas no processo de saúde, doença ou terminalidade deve estar esclarecido de suas próprias introjeções acerca da vida e da morte para que esteja em alerta quanto ao risco de projetar-se ao próximo sem dar o espaço para que este viva suas situações de sofrimento ao seu modo, mas lhe dando um lugar para chegar e retirando-lhe a capacidade de realizar autonomamente suas necessidades. Ao lidarmos com a situação dolorosa de outrem sem ter a pretensão de retirá-la, curá-la ou resolvê-la, abrimos espaço para acolher necessidades e focar nas suas potencialidades como ser no mundo, naquilo que possui de saudável.

Nessa direção, ressalta-se a importância de que o profissional de saúde, e especialmente o psicólogo, contribua para que o fluxo autorregulativo se estabeleça, promovendo um olhar integral para o ser humano no resgate de suas forças e potencialidades, assegurando-lhe o apoio necessário para que possa ajustar-se de maneira nova e criativa diante dos desafios cotidianos que se estabelecem. Fazendo do encontro um lugar de acolhimento e crescimento, oferecendo para a pessoa em processo de saúde e doença a escuta e a oportunidade de falar sobre suas dores e seus sonhos, retomando o sentido de sua existência e ressignificando, se necessário, seus introjetos referentes à vida.

\section{Considerações Finais}

A Gestalt Terapia é uma abordagem psicológica que sustenta a prática de psicólogos nos mais diversos campos de trabalho. Fez-se possível perceber através deste trabalho que muito pode ser feito para propiciar uma experiência diferente ante os processos de saúde e doença e de morte e morrer. Algumas limitações foram encontradas neste estudo e serão apresentadas a fim de incentivar o desenvolvimento de futuras pesquisas que visem preencher lacunas teóricas e ampliar o conhecimento sobre os fenômenos articulados. Destaca-se a dificuldade de encontrar na literatura nacional, sobretudo na produção científica da Psicologia, estudos que aprofundem o conceito de esperança, fato que se mostrou enquanto limitador à discussão teórica e dos resultados encontrados, bem como a produção acadêmica que relacione a Gestalt Terapia com a esperança diante dos processos de adoecimento e morte.

Dessa forma, entende-se que esse estudo contribui para o avanço do conhecimento sobre as vivências diante da saúde, doença e morte a partir de uma visão existencial fenomenológica, posto que a perspectiva gestáltica oferta possibilidades para a ressignificação de processos uma vez que propõe a tomada de consciência, incentiva o autossuporte e o desenvolvimento de potencialidades; por modo que as pessoas envoltas dessa situação saibam onde buscar, através do auto e heterossuporte, recursos de enfrentamento para a doença.

Nota-se que diversos estudos enxergam na esperança um dos recursos de enfrentamento fundamentais no processo de adoecimento, os artigos analisados pressupõem que a esperança é de fato benéfica para a saúde. Deste modo, podemos pensá-la enquanto um ajustamento criativo que responde bem à necessidade emergente que a situação impõe; uma vez que ter esperança é deparar-se com as limitações, mas perceber simultaneamente a existência de oportunidades (Magão \& Leal, 2001). Ainda, é importante sensibilizar o olhar para os familiares, cuidadores e seres queridos de pessoas em situação 
de adoecimento, pois a manutenção da esperança diante dessa situação relaciona-se com ter algo ou alguém para quem viver.

Perls (1977) teve como perspectiva transformar pessoas de papel em pessoas de carne e osso, retomando o sentido de estar vivo e de sermos quem somos na autenticidade e espontaneidade. Como gestalt terapeutas, o reconhecimento das interrupções de contato e formas de ajustamento nos orienta de forma mais intuitiva para as intervenções. Intervir nos ajustamentos interrompidos que aparecem no campo faz-se necessário, mas, sobretudo, é na visualização daquilo que se tem de saudável que se encontra a deixa para a restauração da autonomia e de ajustamentos funcionais; no resgate da fluidez do fluxo figura e fundo almejando o processo de atualização e transformação. Ou seja, uma abertura para o novo, para o retorno da criação; e é essa a contribuição que podemos oferecer diante de uma situação ameaçadora como a vivência de uma doença agravada ou terminalidade da vida.

Há um fio de esperança que transcende às dificuldades e abrilhanta as adversidades nas situações de crise. Até mesmo diante da morte, o ser humano está à espera de uma passagem para um mundo melhor ou do fim de seu sofrimento; diante da vida, a espera para o encontro com algo ou com alguém se expressa de forma imensurável. Faz-se necessário a sutileza e a sensibilidade do olhar e do ouvir acerca da historicidade de cada indivíduo em que se há o privilégio do encontro, dedicando-se ao que é melhor possível no momento, possibilitando a esperança apesar de.

\section{Referências}

Balsanelli, A. C. S., Grossi, S. A. A., \& Herth, K. (2011). Avaliação da esperança em pacientes com doença crônica e em familiares ou cuidadores. Acta Paul Enferm, 24(3), 354-8.

Benedetti, G. M. S., Garanhani, M. L, \& Sales, C. A. (2015). The treatment of childhood cancer: unveiling the experience of parents. Rev. Latino-Am. Enfermagem, 22(3), 425-431.

Benzein, E., Norberg, A., \& Saveman, B. I. (2001). The meaning of the lived experience of hope in patients with cancer in palliative home care. Palliative Medicine, 15 (2), 117-126.

Borges, A. A., Lima, R. A. G. de, \& Dupas, G. (2016). Segredos e verdades no processo comunicacional da família com a criança com câncer. Escola Anna Nery, 20(4).

Borges, Z. C., \& Silva, M. H. J. F. (2010). Promoción de la esperanza y resiliencia familiar: Prácticas apreciativas. Investigación y Educación en Enfermería, 28(2), 250-257.
Borges Alves, C., \& Dulci, P. (2014). Quando a morte não tem mais poder: considerações sobre uma obra de Elisabeth Kübler-Ross. Revista Bioética, 22(2), 262-270.

Brandão, J. S. (1992). Dicionário mítico-etimológico da mitologia grega. Petrópolis: Vozes.

Caires, S., Machado, M., Antunes, M. C., \& Melo, A. S. M. (2018). Recidiva oncológica: olhares dos profissionais hospitalares sobre as dificuldades do paciente pediátrico. Psico-USF, 23(2), 333-345. https://dx.doi.org/10.1590/141382712018230212

Cardella, B. H. P. (2014). Ajustamento criativo e a hierarquia de valores ou necessidades. In L. Frazão \& K. O. Fukumitsu, Gestalt-terapia - conceitos fundamentais. São Paulo: Summus.

Cavaco, V. J., Guerreiro, H. J., Reis, S. L. P. L., Alves, A. L., Martins, A. M., \& Santos, M. G. (2010). Qual o papel da esperança na saúde da pessoa? - Revisão Sistemática. Revista de Enfermagem Referência, II(12), 93-103.

Ciporah, S., Tadmor, R., \& Weyl Ben-Arush, M. (2012). Education in pediatric oncology: Learning and reintegration into school. In S. Kreitler, M. W. Bem-Arush \& A. Martin (Eds.), Pediatric psycho-oncology: Psychosocial aspects and clinical interventions. (2nd edition, pp. 104-116). West Sussex, UK: John Wiley \& Sons.

Bloch, E. (2005). O princípio esperança. Rio de Janeiro: UERJ/Contraponto.

Espíndula, J. A., \& Valle, E. R. M. (2002). Experiência materna diante da iminência de morte do filho com recidiva de câncer. Pediatri. Mod., 38(5), 188-194.

Ferreira, P. D., \& Mendes, T. N. (2013). Família em UTI: Importância do Suporte Psicológico Diante da Iminência de Morte. Rev. SBPH, 16(1), 88-112.

Fukumitsu, K. O. (2009). O cuidado na saúde e na doença: uma perspectiva gestáltica. Estudos e Pesquisas em Psicologia (UERJ), 9(1), 174-194.

Galvão, C. M., Sawada, N. O., \& Trevizan, M. A. (2004). Revisão sistemática: recurso que proporciona a incorporação das evidências na prática da enfermagem. Rev Latino-am Enfermagem, 12(3), 549-56.

Kiely, B. E., Martin, A., Tattersall, M., Nowak, A., Goldstein, D., Wilcken, N., Wyld, D., Abdi, E., Glasgow, A., Beale, P., Jefford, M., Glare, P., \& Stockler, M. (2013) The Median Informs the Message: Accuracy of Individualized Scenarios for Survival Time Based on Oncologists' Estimates. JournalofClinicalOncology, 31(29), 3565-3571. 
Kovács, M. J. (2003). Educação para a morte: Desafio na formação de profissionais de saúde e educação. São Paulo: Casa do Psicólogo.

Kovács, M. J. (2007). Perdas e o processo de luto. In D. Incontri \& F. S. Santos (Eds.). A arte de morrer. Visões plurais (pp. 217-238). São Paulo: Comenius.

Kübler-Ross, E. (2005). Sobre a Morte e o Morrer. São Paulo: Martins Fontes.

Latner, J. (1994). Fundamentos de la Gestalt. Santiago de Chile: Cuatro Vientos.

Lima, P. A. (2014). Autorregulação organísmica e homeostase. In L. Frazão \& K. O. Fukumitsu, Gestalt-terapia - conceitos fundamentais. São Paulo: Summus.

Magão, M. T. G, \& Leal, I. P. (2001). A promoção da esperança nos pais de crianças com cancro: uma análise fenomenológica interpretativa da relação com profissionais de saúde. Psicol Saúde Doenças, 2(1), 3-22.

Mendes, J. A., Lustosa, M. A., \& Andrade, M. C. M. (2009). Paciente terminal, família e equipe de saúde. Revista da SBPH, 12(1), 151-173.

Menezes, R. A. (2013). A medicalização da esperança: reflexões em torno de vida, saúde/doença e morte. Amazônica, Revista de Antropologia, 5(2), 478-498.

Misko, M. D., Santos, M. R. dos, Ichikawa, C. R. F., Lima, R. A. G., \& Bousso, R. S. (2015). The family's experience of the child and/or teenager in palliative care: fluctuating between hope and hopelessness in a world changed by losses. Revista Latino- $A$ mericana de Enfermagem, 23(3), 560-567. https:// dx.doi.org/10.1590/0104-1169.0468.2588

Moreno, R. L. R., Jorge, M. S. B., \& Moreira, R. V. O. (2003). Vivências maternais em unidade de terapia intensiva: um olhar fenomenológico. Revista Brasileira de Enfermagem, 56(3), 282-287.

Perls, F. (1977). Gestalt-terapia explicada. São Paulo: Summus.

Perls, F. (1981). A abordagem gestáltica e a testemunha ocular da terapia. Rio de Janeiro: Zahar.

Perls, F. (1988). A abordagem gestáltica e a testemunha ocular da terapia. Rio de Janeiro: Guanabara.

Perls, F., Hefferline, R., Goodman, P. (1997). Gestalt-terapia. São Paulo: Summus.

Pinto, S., Caldeira, S., \& Martins, J. C. (2012). Hope of cancer patients: research in the context of chemotherapy. Revista de Enfermagem Referência, 3(7), 23-31. https://dx.doi.org/10.12707/RIII11148
Quintana, A. M., Kegler, P., Santos, M., S., \& Lima, L. D. (2006). Sentimento e percepções da equipe de saúde frente ao paciente terminal. Paidéia (Ribeirão Preto), 16(35), 415-425.

Robine, J-M. (2006). O self desdobrado: perspectiva de campo em Gestalt-terapia. São Paulo: Summus.

Schillings, A. (2010). A violência no contexto intrafamiliar e social: um olhar da gestalt-terapia às vivências opressivas. Sampa GT, 6, 45-51.

Schillings, A. (2014). Concepção de neurose em Gestalt-terapia. In L. Frazão \& K. O. Fukumitsu, Gestalt-terapia - conceitos fundamentais. São Paulo: Summus.

Silva, M. L. C. da, \& Alencar, S. O. (2011). Gestalt-terapia e corpo: uma revisão literária. IGT na Rede, 8(15), 335-368.

Snyder, C. R. (2000). The past and future of hope. Journal of Social and Clinical Psychology, 19, pp. 11-28.

Snyder, C. R., Cheavens, J., \& Sympson, S. C. (1997). Hope: an individual motive for social commerce. Group Dynamics: Theory, Research and Practice, 1, pp. 107-118.

Snyder, C. R., \& Lopez, S. (2009). Psicologia positiva. Porto Alegre: Artmed.

Souza, E. N., Oliveira, N. A. de, Luchesi, B. M., Gratão, A. C. M., Orlandi, F. S, \& Pavarini, S. C. I. (2017). Relação entre a esperança e a espiritualidade de idosos cuidadores. Texto $\mathcal{O}$ Contexto - Enfermagem, 26(3), 10-17.

Bruna Berri (orcid.org/0000-0003-4589-3909). Psicóloga pela Universidade Federal de Santa Catarina. Mestra em Psicologia pelo Programa de Pós Graduação da Universidade Federal de Santa Catarina, na área de Saúde e Desenvolvimento Psicológico. Especialista em Saúde da Mulher e da Criança pelo programa de Residência Integrada Multiprofissional em Saúde - HU/UFSC. Gestaltterapeuta formada pelo Comunidade Gestáltica (Florianópolis). Email: brunaberri@hotmail.com

Recebido em: 31/01/2019

Primeira Decisão Editorial: 01/07/2019

Aceito em: 17/10/2019 